\title{
Active Management of Third Stage of Labor: Practice and Associated Factors among Obstetric Care Providers in North Wollo, Amhara Region, Ethiopia
}

\author{
Wondwosen Molla $\mathbb{D D}^{1}{ }^{1}$ Asresash Demissie ${ }^{(D)},{ }^{2}$ and Marta Tessema ${ }^{3}{ }^{3}$ \\ ${ }^{1}$ Department of Midwifery, College of Medicine and Health Science, Dilla University, Dilla, Ethiopia \\ ${ }^{2}$ School of Nursing, Faculty of Health Science, Institute of Health, Jimma University, Jimma, Ethiopia \\ ${ }^{3}$ School of Midwifery, Faculty of Health Science, Institute of Health, Jimma University, Jimma, Ethiopia \\ Correspondence should be addressed to Wondwosen Molla; wondwosenm955@gmail.com
}

Received 25 July 2021; Accepted 6 December 2021; Published 31 December 2021

Academic Editor: Joseph I. Ikechebelu

Copyright (c) 2021 Wondwosen Molla et al. This is an open access article distributed under the Creative Commons Attribution License, which permits unrestricted use, distribution, and reproduction in any medium, provided the original work is properly cited.

\begin{abstract}
Background. World Health Organization strongly recommends that every obstetrical provider at birth needs to have knowledge and skills on active management of the third stage of labor and use it routinely for all women. However, implementation of this lifesaver intervention by skilled birth attendants is questionable because $3 \%$ to $16.5 \%$ of women still experience postpartum hemorrhage. Even though coverage of giving births at health facilities in Ethiopia increases, postpartum hemorrhage accounts for $12.2 \%$ of all maternal deaths occurring in the country. Lack of the necessary skills of birth attendants is a major contributor to these adverse birth outcomes. Objectives. This study aimed to assess the active management of the third stage of labor practice and associated factors among obstetric care providers. Methods. An institution-based cross-sectional study design was applied from March 15 to April 15, 2020. Multistage sampling techniques were used to get 254 participants, and data were collected using selfadministered structured questionnaires and an observation checklist. Data were entered into EpiData version 3.1 and exported to Statistical Package for the Social Sciences (SPSS) version 23.0 for analyses. The multivariable logistic regression model was used at $95 \%$ confidence interval with $P$ value $<0.05$. Among the 232 providers participating in the study, only $75(32.3 \%)$ of respondents had a good practice. The practice of the provider was significantly associated with work experience (adjusted odd ratio 0.206 ( $95 \%$ confidence interval, 0.06-0.63)), knowledge (adjusted odd ratio (2.98 (95\% confidence interval, 1.45-6.14)), the presence of assistance (adjusted odd ratio 2.04 (95\% confidence interval, 1.06-3.93)), and time of uterotonic drug preparation (adjusted odd ratio 4.69 (95\% confidence interval, 2.31-9.53)). Conclusion. Only one-third of obstetric care providers had good practice during active management of third stage of labor. Practice was significantly associated with work experience, knowledge, the presence of assistance during third-stage management, and time of uterotonic drug preparation. Consistent and sustainable on job training and clinical audit should be applied in all facilities with regular supportive supervision and monitoring. Furthermore, team work and adequate preparation should be done to facilitate the management of active third stage of labor.
\end{abstract}

\section{Introduction}

Active management of the third stage of labor (AMTSL) is a combination of intervention performed by skilled birth attendant designed to facilitate the delivery of the placenta by increasing uterine contraction during the third stage of labor and also used to prevent postpartum hemorrhage $(\mathrm{PPH})$ by averting uterine atony $[1,2]$.
According to FIGO-ICM and WHO, the usual components of AMTSL are the use of uterotonic agent in the first steps, preferably IM 10 IU oxytocin immediately within $1 \mathrm{~min}$ of delivery after ruling out the possibility of second baby to all births. Then, applying controlled cord traction (CCT) with the clamping of the cord within 1-3 minutes after birth is the second step for delivery of the placenta $[3,4]$. 
The global target for ending preventable maternal mortality by 2030 recommends that every country should reduce its MMR by at least two-thirds from the 2016 baseline, and no country should have an MMR higher than 140 deaths per 100,000 live births (twice the global target) $[5,6]$. In Ethiopia, the maternal mortality ratio was 412 / 100.000 live births in 2016 [7]. This number showed that MMR in our country is six times higher than the baseline, 140 deaths/100,000 live births [8].

Maternal mortality has sharply decreased by $43 \%$ worldwide $[9,10]$. AMTSL plays an important role in preventing $27 \%$ of maternal deaths, $60 \%$ of $\mathrm{PPH}$, and the use of blood transfusions $[11,12]$. However, about $3 \%$ to $16.5 \%$ of women still experience $\mathrm{PPH}$ and require treatment [13-15]. Every pregnant woman may face life-threatening blood loss during delivery. FIGO-ICM strongly recommends that every obstetrical provider at birth needs to have knowledge, skills, and critical judgment to carry out AMTSL $[1,3]$.

$\mathrm{PPH}$ is one of the leading causes of maternal death worldwide. It occurs in $25 \%$ of all maternal deaths worldwide [4, 5], 34\% in Africa [16], and $12.2 \%$ in Ethiopia [17], especially in settings where there are no birth attendants or where they lack the necessary skilled birth attendants and equipment to prevent and manage PPH and shock [12]. The majority of these deaths are preventable by adopting simple, effective, and safe strategies such as AMTSL $[9,16,18]$.

Routine use of AMTSL by skilled birth attendants at health facilities for all vaginal singleton birth is recommended by the IFGO-ICM and WHO $[3,19]$. All laboring women are at risk for $\mathrm{PPH}$, so all obstetric care providers should have knowledge and skills regarding AMTSL intervention to prevent PPH [20].

The implementation of AMTSL intervention by skilled birth attendants is questionable because the incidence of $\mathrm{PPH}$ keeps rising $[4,13,21]$. However, studies have identified a gap in the use of AMTSL. In a global survey, it was found that only $16(43 \%)$ of 37 investigated countries included the administration of a uterotonic/AMTSL in their national health management information systems [22]. A study conducted in seven Sub-Saharan countries reported that the AMTSL was only implemented correctly in $0.5-32 \%$ of the observed deliveries [23] whereas only $47 \%$ in Ethiopia [24].

\section{Materials and Methods}

2.1. Study Design and Setting. An institutional-based crosssectional study design was conducted from March 15 to April 15, 2020, at governmental health facilities of Northeastern, Ethiopia.

\subsection{Population}

2.2.1. Source Populations. The study included all obstetric care providers working in the maternity unit at North Wollo Health Facilities.
2.2.2. Study Populations. The study included all obstetric care providers working at selected health facilities.

\subsection{Inclusion and Exclusion Criteria}

2.3.1. Inclusion Criteria. All obstetric care providers working in the maternity unit were included in this study.

2.3.2. Exclusion Criteria. Obstetric care providers who were not volunteers and those on annual leaves were excluded from the study.

2.4. Sample Size Determination. For two outcome variables, the sample size was determined using single population proportion formula by considering the following assumptions:

$$
n=\frac{\left(Z_{-} \alpha / 2\right)^{2} * P(1-P)}{d^{2}},
$$

where $n=$ sample size required for the study and $p=$ the proportion of practice $(32.8 \%)$ on AMTSL in Sidama Zone, South Ethiopia [14]. $Z=Z \alpha / 2=1.96$, corresponding to a $95 \%$ confidence level. $d=$ the margin of error $=0.05$.

For practice,

$$
n=\frac{(1.96)^{2} * 0.328(0.672)}{0.05^{2}}
$$

where $n=338.7$ approximately 339 .

However, only 268 obstetric care providers were working at the selected health facilities. Because the population is less than 10,000, the study considered correction formula by taken 361 to get the maximum sample size:

$$
\begin{aligned}
n f & =\frac{n i}{1+(n i / N)}, \\
n f & =\frac{361}{1+(361 / 268)}, \\
n & =153.8 \sim 154 .
\end{aligned}
$$

Since multistage sampling technique was used, the sample size was multiplied by the design effect of $\mathbf{1 . 5}$ :

$$
n=1.5 * 154=231 \text {. }
$$

For possible none response rate, the final sample size was increased by $10 \%$ to

$$
n=254
$$

The sample size for associated factors was determined using Epi Info 7 as shown in Table 1.

Therefore, the largest sample size was $(n=254)$.

2.5. Sampling Techniques. Multistage sampling technique was used. Initially, out of 14 districts of the zone, five were selected using simple random sampling techniques (lottery methods): Lalibela districts, Wolidya districts, Mersa 
TABLE 1: Sample size determination using Epi Info for factors associated with practice.

\begin{tabular}{lccccc}
\hline \multirow{2}{*}{ Factors associated with practice } & \multicolumn{5}{c}{ Assumption } \\
& CI (\%) & OR & Ratio & \% of outcome in unexposed & Final sample size \\
\hline Access to reading materials & 95 & 3.1 & $1: 0$ & 31.8 & 36.3 \\
Knowledge & 95 & 3.2 & $1: 0$ & 60.0 & 118 \\
Qualification & 95 & 5.5 & $1: 0$ & 45.4 & 82 \\
Sex & 95 & 5.6 & $1: 0$ & 27.27 & 62 \\
Pre/in-service training & 95 & 8.7 & $1: 0$ & 38 \\
\hline
\end{tabular}

town, Wadila woreda, and Bugina woreda. There were 17 health facilities at the selected districts with a total of 268 obstetrics care providers. All the health institutions were included in this study. Then the final sample size was allocated proportionally for each health facility based on their number of obstetrical care providers. Respondents were selected by simple random sampling technique using the list of the professionals working in the delivery ward from the human resource management as a sampling frame, as shown in Figure 1.

2.6. Data Collection Tool and Data Quality Assurances. A standard questionnaire was adapted from the ICM and FIGO guidelines (1). It was prepared in English. Self-administered structured questionnaires and observation checks lists were used separately. Self-administered structured questionnaires have four parts: sociodemographic characteristics (9 items), training factors ( 7 items), health facility factors (7 items), and knowledge assessment (11 items). Moreover, the observation checklist part has 16 items. The level of knowledge was determined using 11 questions. Participants who scored below the median were considered to have poor knowledge. In contrast, participants who scored equal or above the median score were considered to have good knowledge. The level of practice was measured based on a series of 16 steps. Good practice: those who followed 16 steps of the checklist correctly while conducting AMTSL. Poor practice: those who did not follow at least one step of the checklist correctly.

A pretest was conducted on 5\% of the sample size other than the study area. To minimize the effect of personal and professional relationships, observers were selected from outside of the study facilities. Cronbach's alpha was done to check the reliability. It was 0.84 for knowledge and 0.77 for practice. Eight data collectors and four supervisors who had Basic Emergency Obstetric and Neonatal Care (BEmONC) and Comprehensive Emergency Obstetric and Neonatal Care (CEmONC) training were recruited, and two days of training were given for both. Providers were not aware of the contents and items on the checklists. To minimize the effect of observation on the provider behavior (hawthorn effect), providers were assured the data collected were anonymous and individual performance would not be reported to their supervisors or shared publically (published reports only refer to aggregate data).

The birth attendants were observed while conducting the third stage of labor using the observational checklist. Then, self-administered structured questionnaires were distributed to respondents who participated in the observational part of the study. Data were collected and signed by supervisors after checking the filed questionnaire for any missing items and correctness. Besides, there was continuous follow-up and supervision by the principal investigator throughout the data collection period, and also necessary feedback was provided for supervisors and data collectors. All questionnaires and observation checklists were kept under lock and key for security and confidentiality of obtained information.

2.7. Data Analysis. Data were first checked manually for completeness, then coded and entered into EpiData version 3.1, and exported to SPSS version 23.0 for analyses. Exploratory data analysis was done to check missing values and outliers. The model fitness test was checked by Hosmer and Lemeshow test. The value was 0.869 for knowledge and 0.878 for practice. Binary and multivariable logistic regression analysis was done. Variables that had $P$ value less than 0.25 in binary logistic regression were taken as a candidate for multivariable logistic regression. Finally, in multivariable logistic regression, variables with 95\% CI at $P$ value less than 0.05 were considered statistically significant.

\section{Result and Discussion}

3.1. Sociodemographic Characteristics of Respondents. From a total of 254 obstetric care providers included in the study, about 232 participated with an overall response rate of $91.3 \%$. One hundred thirty-five (86\%) participants were found in the age group of 25-30 years with a mean age of 28.7 years and a standard deviation $( \pm S D)$ of 4.069 , as shown in Table 2.

3.2. Health Institution and Training Information of Respondents. More than half (68.1\%) of the participants were working at the health center, and almost all 229 (98.7\%) and 226 (97.4\%) of them had adequate oxytocin drugs and refrigerators in their workplace, respectively. About $35.3 \%$ of providers have in-service training as shown in Table 3.

3.3. Practice Obstetric Care Provider on AMTSL. Only $32.3 \%$ of providers had a good practice on AMTSL in Figure 2. Moreover, the three components of AMTSL were more practiced among midwives compared to other professions as indicated in Table 4. 


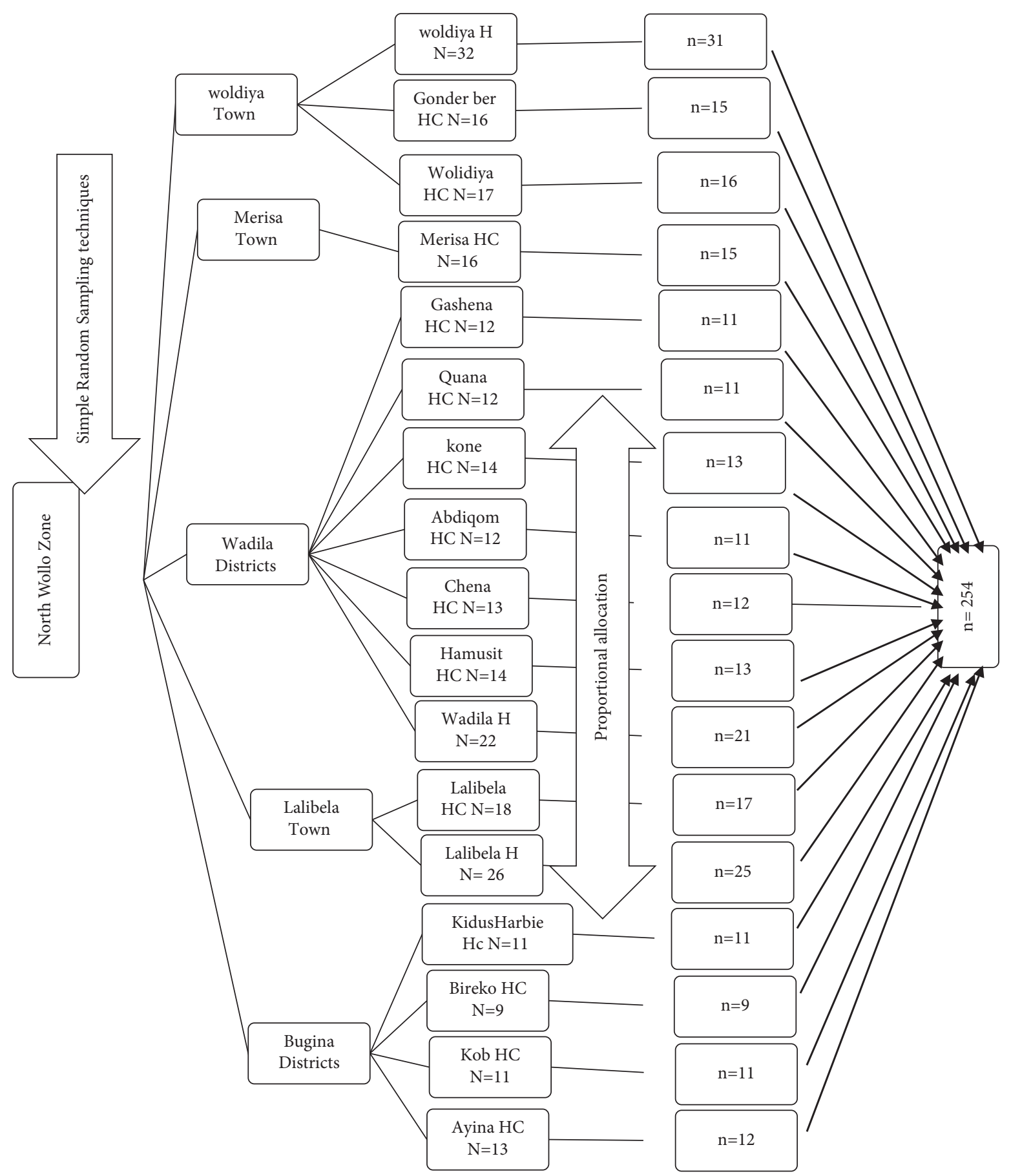

FIgURE 1: Schematic presentation of sampling procedure of the study. HC: health center, H: hospital, N: total number, n: sample.

3.4. Knowledge of Obstetric Care Provider on AMTSL. Only $53.4 \%$ of respondents had good knowledge of AMTSL, as shown in Table 5. Furthermore, only $42.7 \%$ of respondents answered correctly about the administration of the uterotonic drug as a critical element of AMTSL. About $76.3 \%$ of providers responded that the time of cord clamping should be between 1 and 3 minutes.

3.5. Factors Associated with Practice of Obstetric Care Providers towards AMTSL. In multivariable logistic regression, the AMTSL practice of providers is significantly associated with work experience, knowledge on AMTSL, the presence of assistance during third-stage management, and time of uterotonic preparation, as shown in Table 6.

\section{Discussion}

4.1. Practice of Obstetric Care Provider on AMTSL. In this study, only $32.3 \%$ of providers followed AMTSL steps appropriately. It is almost in line with the study conducted in Sidama Zone (32.8\%) [14], higher than the study done in 
TABLe 2: Sociodemographic characteristic of participants, 2020.

\begin{tabular}{|c|c|c|c|}
\hline Variable & Category & Frequency & Percent \\
\hline \multirow{4}{*}{ Age } & $<25$ & 49 & 21 \\
\hline & $25-30$ & 135 & 58.2 \\
\hline & $31-35$ & 34 & 14.8 \\
\hline & $>35$ & 14 & 6.0 \\
\hline \multirow{2}{*}{ Sex } & Female & 104 & 44.8 \\
\hline & Male & 128 & 55.2 \\
\hline \multirow{4}{*}{ Marital status } & Married & 121 & 52.2 \\
\hline & Not married & 100 & 43.1 \\
\hline & Divorced & 8 & 3.4 \\
\hline & Widowed & 3 & 1.3 \\
\hline \multirow{4}{*}{ Ethnicity } & Amhara & 159 & 68.5 \\
\hline & Oromo & 22 & 9.5 \\
\hline & Tigre & 47 & 20.3 \\
\hline & Others* & 4 & 1.7 \\
\hline \multirow{3}{*}{ Religion } & Orthodox & 168 & 72.4 \\
\hline & Muslim & 47 & 20.3 \\
\hline & Protestant & 17 & 7.3 \\
\hline \multirow{4}{*}{ Profession } & General practitioner & 42 & 18.1 \\
\hline & Health officer & 32 & 13.8 \\
\hline & Midwife & 87 & 37.5 \\
\hline & Nurse & 71 & 30.6 \\
\hline \multirow{3}{*}{ Qualification } & Diploma $^{* *}$ & 54 & 23.3 \\
\hline & Advanced diploma*** & 32 & 13.8 \\
\hline & Degree $^{* * * *}$ & 146 & 62.9 \\
\hline \multirow{3}{*}{ Year of graduation } & $<2000$ & 1 & 4 \\
\hline & 2000-2005 & 87 & 37.5 \\
\hline & $>2005$ & 144 & 62.1 \\
\hline \multirow{4}{*}{ Work experience } & $<12$ months & 41 & 17.7 \\
\hline & $12-24$ months & 38 & 16.3 \\
\hline & $25-36$ months & 48 & 20.7 \\
\hline & $>36$ months & 105 & 45.3 \\
\hline
\end{tabular}

Others* such as Afar, Gurage. Diploma**: certificate given after two years of higher education training. Advanced diploma ${ }^{* * *}$ : type of diploma given after three years of higher education studies, just below the achievement of bachelor's degree. Degree ${ }^{* * * *}$ : bachelor's degree.

TABLE 3: Health institution and training information of respondents, 2020.

\begin{tabular}{lccc}
\hline Variable & Category & Frequency & Percent (\%) \\
\hline \multirow{2}{*}{ Facility } & Hospital & 74 & 31.9 \\
& Health center & 158 & 68.1 \\
\hline \multirow{2}{*}{ Reading material } & Yes & 116 & 50 \\
& No & 116 & 50 \\
\multirow{2}{*}{ Favorable delivery ward } & Yes & 225 & 7 \\
\\
\multirow{2}{*}{ Adequate uterotonic drug } & No & 229 & 3 \\
& Yes & 3 & 98.7 \\
\multirow{2}{*}{ Refrigerator } & No & 226 & 1.3 \\
& Yes & 8 & 97.4 \\
\multirow{2}{*}{ Training on AMTSL } & No & 150 & 2.6 \\
& Preservice & 82 & 35.3 \\
\hline
\end{tabular}

Sudan (26.7\%) [25] and (16.7\%) Hawassa city [26], and lower than the studies conducted in Addis Ababa (47\%) [24], Nigeria (78\%) [27], and Netherlands (48\%) [25]. The discrepancy might be due to knowledge gap, variation in study setting (in this study, both hospital and health center were included), and study participants (different disciplines included in this study).

Preloading uterotonic drugs before the third stage of labor, having assistant during third stage management, inservice training, work experience, and knowledge on 
Practice of Obstatrical Care Providers

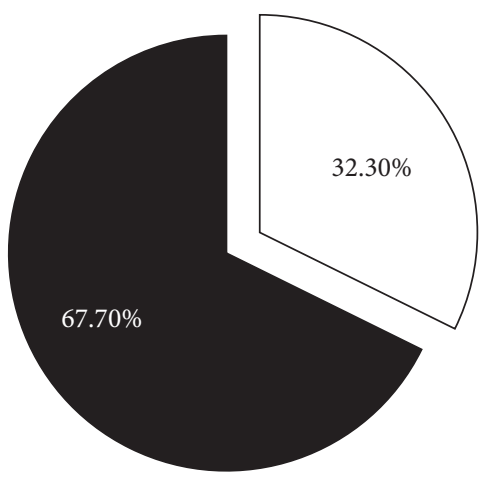

$\square$ Good Practice

Poor Practice

FIgUre 2: Practice of obstetric care provider on AMTSL at governmental health facilities in North Wollo, Amhara region, Ethiopia, 2020.

TABLe 4: Practice of obstetric care provider on AMTSL, 2020.

\begin{tabular}{|c|c|c|c|}
\hline Variables & Categories & Frequency & Percentage \\
\hline \multirow{2}{*}{ Checked presence of another fetus } & Yes & 200 & 86.2 \\
\hline & No & 32 & 13.8 \\
\hline \multirow{2}{*}{ Correct timing of administration uterotonic drug } & Yes & 192 & 82.8 \\
\hline & No & 40 & 17.2 \\
\hline \multirow{2}{*}{ Types of uterotonic drugs given } & Oxytocin & 223 & 96.1 \\
\hline & Ergometrine & 9 & 3.9 \\
\hline \multirow{2}{*}{ Correct dose of uterotonic drugs given } & Yes & 217 & 93.5 \\
\hline & No & 15 & 6.5 \\
\hline \multirow{2}{*}{ Correct mode of administration of uterotonic drugs } & Yes & 225 & 97 \\
\hline & No & 7 & 3 \\
\hline \multirow{2}{*}{ Correct timing of cord clamping } & Yes & 169 & 72.8 \\
\hline & No & 63 & 27.2 \\
\hline \multirow{2}{*}{ Wait for uterine contraction $2-3 \mathrm{~min}$ to apply CCT } & Yes & 182 & 78.4 \\
\hline & No & 50 & 21.6 \\
\hline \multirow{2}{*}{ Wait for gush of blood to apply cord control traction } & Yes & 201 & 86.6 \\
\hline & No & 31 & 13.4 \\
\hline \multirow{2}{*}{ Placenta delivered before uterotonics administration } & Yes & 66 & 28.4 \\
\hline & No & 166 & 71.6 \\
\hline \multirow{2}{*}{ CCT performed as protocol } & Yes & 178 & 76.7 \\
\hline & No & 54 & 23.3 \\
\hline \multirow{2}{*}{ Placenta was supported by both hands } & Yes & 205 & 88.4 \\
\hline & No & 27 & 11.6 \\
\hline \multirow{2}{*}{ Membrane extracted gently with lateral movement } & Yes & 205 & 88.4 \\
\hline & No & 27 & 11.6 \\
\hline \multirow{2}{*}{ Uterine massage immediately after delivery of placenta } & Yes & 219 & 94.4 \\
\hline & No & 13 & 5.6 \\
\hline \multirow{2}{*}{ Placenta assessed for completeness } & Yes & 220 & 94.8 \\
\hline & No & 12 & 5.2 \\
\hline \multirow{2}{*}{ Uterine relaxation ensured } & Yes & 203 & 87.5 \\
\hline & No & 29 & 12.5 \\
\hline \multirow{2}{*}{ Inform and demonstrate the mother massage uterus } & Yes & 205 & 88.4 \\
\hline & No & 27 & 11.6 \\
\hline \multirow{2}{*}{ Overall practice } & Good & 75 & $32.3 \%$ \\
\hline & Poor & 157 & $67.7 \%$ \\
\hline
\end{tabular}


TABLE 5: Knowledge of obstetric care provider on AMTSL, 2010.

\begin{tabular}{|c|c|c|c|c|}
\hline \multirow{2}{*}{ Variables } & \multicolumn{4}{|c|}{ Categories } \\
\hline & Yes & $(\%)$ & No & $(\%)$ \\
\hline Know critical elements of the AMTSL & 99 & 42.7 & 133 & 57.3 \\
\hline $\begin{array}{l}\text { Know recommended immediate role of obstetric } \\
\text { care providers after delivery of fetus }\end{array}$ & 184 & 79.3 & 48 & 20.7 \\
\hline Know recommended first-line uterotonics drugs & 215 & 92.7 & 17 & 7.3 \\
\hline Know recommended dose of oxytocin & 201 & 86.6 & 31 & 13.4 \\
\hline Know recommended route of oxytocin & 214 & 92.2 & 18 & 7.8 \\
\hline Know three main sequential components of AMTSL & 202 & 87.1 & 30 & 12.9 \\
\hline Know time to administer uterotonics & 201 & 86.6 & 31 & 13.4 \\
\hline Know recommended time to clamp the cord & 177 & 76.3 & 55 & 23.7 \\
\hline $\begin{array}{l}\text { Know the frequency of performing uterine massage } \\
\text { over the first two hours }\end{array}$ & 184 & 79.3 & 48 & 20.7 \\
\hline Know time of completing AMTSL & 138 & 59.5 & 94 & 40.5 \\
\hline Know harmful practices when performing AMTSL & 185 & 79.7 & 47 & 20.3 \\
\hline Adequate knowledge on AMTSL & 124 & $53.4 \%$ & 108 & $46.6 \%$ \\
\hline
\end{tabular}

TABLE 6: Bivariate and multivariable analysis, on factors associated with obstetrics care providers' practice on active management of third stage of labor, 2020.

\begin{tabular}{|c|c|c|c|c|c|}
\hline \multirow{2}{*}{ Variables } & \multicolumn{2}{|c|}{ Practice status } & \multirow{2}{*}{ COR $(95 \% \mathrm{CI})$} & \multirow{2}{*}{$\operatorname{AOR}(95 \% \mathrm{CI})$} & \multirow{2}{*}{$P$ value } \\
\hline & Good & Poor & & & \\
\hline \multicolumn{6}{|l|}{ Work experience } \\
\hline$<12$ months & 5 & 36 & $0.200(0.073-0.552) * *$ & $0.206(0.067-0.635)$ & 0.01 \\
\hline $12-24$ months & 10 & 28 & $0.515(0.227-1.169)$ & $0.654(0.251-1.706)$ & 0.38 \\
\hline $25-36$ months & 17 & 31 & $0.791(0.390-1.605)$ & $0.571(0.252-1.293)$ & 0.17 \\
\hline$>36$ months & 43 & 62 & 1 & 1 & \\
\hline \multicolumn{6}{|c|}{ Manage $3^{\text {rd }}$ stage of labor with assistance } \\
\hline Yes & 43 & 65 & $1.902(1.090-3.320) *$ & $2.045(1.062-3.936)$ & 0.02 \\
\hline No & 32 & 92 & 1 & 1 & \\
\hline \multicolumn{6}{|l|}{ Loading of uterotonic } \\
\hline Yes & 59 & 75 & $4.032(2.136-7.608) * *$ & $4.695(2.311-9.538)$ & 0.01 \\
\hline No & 16 & 82 & 1 & 1 & \\
\hline \multicolumn{6}{|l|}{ Sex } \\
\hline Male & 50 & 78 & $2.026(1.142-3.593) *$ & & \\
\hline Female & 25 & 79 & 1 & & \\
\hline \multicolumn{6}{|l|}{ Profession } \\
\hline GP & 17 & 25 & $2.769(1.184-6.473) *$ & & \\
\hline $\mathrm{HO}$ & 9 & 23 & $1.593(0.606-4.191)$ & & \\
\hline Midwife & 35 & 52 & $2.740(1.327-5.657) * *$ & & \\
\hline Nurse & 14 & 57 & 1 & & \\
\hline \multicolumn{6}{|l|}{ Qualification } \\
\hline Diploma & 10 & 44 & $0.355(0.165-.761) * *$ & & \\
\hline Advanced diploma & 8 & 24 & $0.520(0.219-1.238)$ & & \\
\hline Degree & 57 & 89 & 1 & & \\
\hline \multicolumn{6}{|l|}{ In-service training } \\
\hline Yes & 31 & 51 & $4.026(1.720-9.424) * *$ & & \\
\hline No & 53 & 150 & 1 & & \\
\hline \multicolumn{6}{|c|}{ Knowledge of respondents on AMTSL } \\
\hline Good knowledge & 57 & 67 & $4.254(2.295-7.885) * *$ & $2.986(1.451-6.144)$ & 0.01 \\
\hline Poor knowledge & 18 & 90 & 1 & 1 & \\
\hline
\end{tabular}

Note: $* P<0.05, * * P<0.01,1$ : reference group.

AMTSL had a significant association with the provider's proper application of AMTSL. Considerable studies and different organizations indicate that team work and preparation to attend childbirth is mandatory to manage labor effectively and prevent unpredicted complications $[1,8]$. In line with this, the present study also shows that providers who preloaded uterotonic drugs were 4.6 times more likely to practice AMTSL appropriately than those who did not preload. However, only $57.8 \%$ of care providers prepared uterotonic drugs before they started to attend labor. It is 
lower than the study done in Nepal, which was 99.3\% [28]. The possible justification for this difference might be variation in study design (single-blind) and study setting. The study done in Nepal included only one training center hospital. This gives enhanced chances for the providers to access different on-the-job training that might have helped to update their knowledge. Moreover, providers working in the hospital mostly get experience from a gynecologist and other senior staff. Furthermore, providers who managed the third stage of labor with assistance were 2.0 times more likely to practice AMTSL appropriately compared to those who managed $3^{\text {rd }}$ stage of labor alone. However, still more than half of the providers (about 53.4\%) managed the third stage of labor without the presence of assistance. This is higher than the study conducted in Nigeria, which is $23.7 \%$ [27]. The reason behind this result may be due to patient load and busy clinics. Nevertheless, due to the unpredicted nature of labor, having an assistant is a must.

Providers who had work experience $<12$ months were $79.4 \%$ less likely to practice AMTSL than those who had $>36$ months. This finding has a discrepancy with the study done in Indonesia, which indicates that participants who have less work experience practiced well. The variation might be due to the difference in study participants (research in Indonesia includes only midwives) and providers' burnout (due to workload and little benefits, some providers may develop burnout syndrome and do not do their work properly) [29]. On the contrary, Providers who received in-service training were 7.4 times more likely to practice AMTSL than those who did not. This finding is also supported by the study conducted in Tanzania [30]. In fact, providers who have been taken on in-service training might have better motivation and get practical training. Furthermore, those who had good knowledge of AMTSL were 2.9 times more likely to practice AMTSL than those who had poor knowledge. Similar to the studies conducted in Tanzania, Finfine area Special Zone, Nigeria, and Ghana [27, 30,31]. The reason might be because knowledge brings a change in practice.

4.2. Limitation of the Study. Even if the different technique was carried out to minimize hawthorn effects, direct observations may change the provider's behaviors, so this could affect the results of the study.

\section{Conclusions}

Only one-third of obstetric care providers had good practice during active management of the third stage of labor. Practice is significantly associated with work experience, knowledge, the presence of assistance during third-stage management, and time of uterotonic drug preparation. The federal and regional health biro of the country should focus on updating the obstetric care provider's knowledge and skill by providing consistent and sustainable practice-based AMTSL training if a possible clinical audit should be applied in all facilities with regular supportive supervision and monitoring. Furthermore, the ministry of education should assess the quality of preservice training among health care providers.

\author{
Abbreviations \\ AMTSL: Active management of the third stage of labor \\ AOR: Adjusted odds ratio \\ BEmONC: Basic Emergency Obstetric and Neonatal Care \\ CCT: $\quad$ Controlled cord traction \\ CEmONC: Comprehensive emergency obstetric and \\ neonatal care \\ CI: $\quad$ Confidence interval \\ COR: $\quad$ Crude odds ratio \\ EDHS: Ethiopian Demographic and Health Survey \\ EPIDATA: Epidemiological data version \\ EPIINFO: Epidemiological information \\ FIGO: $\quad$ Federation of International Gynecology and \\ Obstetrics \\ ICM: International confederation of midwives \\ IM: Intramuscular \\ IU: International unit \\ IV: Intravenous \\ OR: $\quad$ Odds ratio \\ PPH: $\quad$ Postpartum hemorrhage \\ SBA: $\quad$ Skilled birth attendant \\ SDG: $\quad$ Sustainable development goals \\ SPSS: $\quad$ Statistical Package for Social Science \\ WHO: World Health Organization.
}

\section{Data Availability}

The data used to support the finding of this study are available from the corresponding author upon request.

\section{Ethical Approval}

Ethical clearance was obtained from Jimma University Institutional Review Board (IRB). A formal letter of permission was obtained from Zonal Health Offices.

\section{Consent}

Written informed consent was obtained from all providers, and verbal consent was obtained from each mother during data collection.

\section{Conflicts of Interest}

The authors declare that they have no conflicts of interests.

\section{Authors' Contributions}

WM conceptualized and designed the study; collected, analyzed, and interpreted the data; and contributed to the drafting of the manuscript. MT designed the study; analyzed and interpreted the data; and contributed to the drafting the manuscript and advising the whole research paper. AD designed the study; analyzed and interpreted the data; and contributed to advising the whole research paper. 


\section{Acknowledgments}

The authors thank Jimma University for financial support, data collectors, supervisors, and study participants.

\section{References}

[1] A. Lalonde, B. A. Daviss, A. Acosta, and K. Herschderfer, "Postpartum hemorrhage today: ICM/FIGO initiative 2004-2006," International Journal of Gynecology \& Obstetrics, vol. 94, no. 3, pp. 243-253, 2006.

[2] D. R. Elbourne, W. J. Prendiville, G. Carroli, J. Wood, and S. McDonald, "Prophylactic use of oxytocin in the third stage of labour," Cochrane Database of Systematic Reviews, no. 4, Article ID CD001808, 2001.

[3] W. H. Organization, WHO Recommendations for the Prevention and Treatment of Postpartum Haemorrhage, World Health Organization, Geneva, Switzerland, 2012.

[4] A. Lalonde, F. S. Motherhood, and N. H. Committee, "Prevention and treatment of postpartum hemorrhage in lowresource settings," International Journal of Gynecology \& Obstetrics, vol. 117, no. 2, pp. 108-118, 2012.

[5] T. Izutsu, A. Tsutsumi, H. Minas, G. Thornicroft, V. Patel, and A. Ito, "Mental health and wellbeing in the sustainable development goals," The Lancet Psychiatry, vol. 2, no. 12, pp. 1052-1054, 2015.

[6] E. Palmer, "Introduction: the 2030 agenda," Journal of Global Ethics, vol. 11, no. 3, pp. 262-269, 2015.

[7] C. E. Demographic, Health Survey-2011. Central Statistical Agency Addis Ababa. Ethiopia ICF International Calverton, Maryland, USA. 2012, 2016.

[8] L. C. Callister and J. E. Edwards, "Sustainable development goals and the ongoing process of reducing maternal mortality," Journal of Obstetric, Gynecologic \& Neonatal Nursing, vol. 46, no. 3, pp. e56-e64, 2017.

[9] H. Emerich Lentz Martins, M. L. de Souza, S. Khanum, N. Naz, and A. C. R. H. Souza, "The practice of nursing in the prevention and control of postpartum hemorrhage: an integrative review," American Journal of Nursing Science, vol. 5, no. 1, pp. 8-15, 2016.

[10] L. Alkema, D. Chou, D. Hogan et al., "Global, regional, and national levels and trends in maternal mortality between 1990 and 2015, with scenario-based projections to 2030: a systematic analysis by the UN maternal mortality estimation inter-agency group," The Lancet, vol. 387, no. 10017, pp. 462-474, 2016.

[11] W. R. Sheldon, J. Durocher, B. Winikoff, J. Blum, and J. Trussell, "How effective are the components of active management of the third stage of labor?" BMC Pregnancy and Childbirth, vol. 13, no. 1, pp. 1-8, 2013.

[12] J. M. Anderson and D. Etches, "Prevention and management of postpartum hemorrhage," American Family Physician, vol. 75, no. 6, pp. 875-882, 2007.

[13] B. P. Ashigbie and B. Pharm, Background Paper 6.16 Postpartum Haemorrhage, 2013.

[14] Z. Tenaw, Z. Yohannes, and A. Amano, "Obstetric care providers' knowledge, practice and associated factors towards active management of third stage of labor in Sidama zone, South Ethiopia," BMC Pregnancy and Childbirth, vol. 17, no. 1, pp. 1-7, 2017.

[15] A. De Groot, T. Vree, H. V. Hogerzeil, and G. Walker, Stability of Oral Oxytocics in Tropical Climates: Results of Simulation Studies on Oral Ergometrine, Oral Methylergometrine, Buccal Oxytocin and Buccal Desamino-Oxytocin.
Stability of Oral Oxytocics in Tropical Climates: Results of Simulation Studies on Oral Ergometrine, oral Methylergometrine, Buccal Oxytocin and Buccal Desamino-Oxytocin/ ANJA de Groot[et al], 1994.

[16] J. M. Smith, R. Gubin, M. M. Holston, J. Fullerton, and N. Prata, "Misoprostol for postpartum hemorrhage prevention at home birth: an integrative review of global implementation experience to date," BMC Pregnancy and Childbirth, vol. 13, no. 1, pp. 44-11, 2013.

[17] G. A. Tessema, C. O. Laurence, Y. A. Melaku, A. Misganaw, S. A. Woldie, and A. Hiruye, "Trends and causes of maternal mortality in Ethiopia during 1990-2013: findings from the global burden of diseases study 2013," BMC Public Health, vol. 17, no. 1, pp. 1-8, 2017.

[18] A. Union, Status Report on Maternal Newborn Child and Adolescent Health: Focusing on Unfinished Business in Africa Second Session of the Specialized Technical Committee on Health, Population and Drug Control (Stc-Hpdc-2) Addis Ababa, Ethiopia, 2017.

[19] Haemorrhage TPP-P, "FIGO/ICM global initiative to prevent post-partum hemorrhage," Journal of Obstetrics Gynaecology Canada, vol. 26, no. 12, pp. 1100-1102, 2004.

[20] W. M. Tan, M. C. Klein, L. Saxell, S. E. Shirkoohy, and G. Asrat, "How do physicians and midwives manage the third stage of labor?" Birth, vol. 35, no. 3, pp. 220-229, 2008.

[21] S. M. Schack, A. Elyas, G. Brew, and K. O. Pettersson, "Experiencing challenges when implementing active management of third stage of labor (AMTSL): a qualitative study with midwives in Accra, Ghana," BMC Pregnancy and Childbirth, vol. 14, no. 1, pp. 193-210, 2014.

[22] Y. M. Kim, N. Ansari, A. Kols et al., "Prevention and management of severe pre-eclampsia/eclampsia in Afghanistan," BMC Pregnancy and Childbirth, vol. 13, no. 1, pp. 186-210, 2013.

[23] C. Stanton, D. Armbruster, R. Knight et al., "Use of active management of the third stage of labour in seven developing countries," SciELO Public Health, 2009.

[24] R. Yaekob, T. Shimelis, A. Henok, and T. Lamaro, "Assessment of knowledge, attitude, and practice of midwives on active management of third stage of labour at selected health centers of Addis Ababa, Ethiopia, 2014," Assessment, vol. 5, no. 11, 2015.

[25] N. Andugry, A. Abdalla, A. Abdalla, S. Mohammed, A. Elnasry, and O. Hospital, "Determinants of midwifery practice in the active management of third stage of labor in omdurman state, Sudan," International Journal of Health Sciences and Research, vol. 7, pp. 224-228, 2017.

[26] Z. Tenaw, Z. Yohannes, and M. Abebe, "Obstetric care providers knowledge and practice towards active management of third stage of Labourat Hawassa city, SNNPRS, Ethiopia," Diversity \& Equality in Health and Care, vol. 13, no. $6,2016$.

[27] M. Oyetunde and C. Nkwonta, “Assessment of midwives' competence in active management of third stage of labour in primary health centres in Anambra state, Nigeria," Journal of Applied Medical Sciences, vol. 4, no. 2, pp. 17-29, 2015.

[28] M. Upadhyay, G. Sharma, and D. Chataut, "Active management of third stage of labor: assessment of standard of care in one of the training institute," Nepal Journal of Obstetrics and Gynaecology, vol. 1, no. 2, pp. 28-30, 2006.

[29] B. W. Prick, A. A. Vos, W. C. J. Hop, H. A. Bremer, E. A. P. Steegers, and J. J. Duvekot, "The current state of active third stage management to prevent postpartum hemorrhage: a 
cross-sectional study," Acta Obstetricia et Gynecologica Scandinavica, vol. 92, no. 11, pp. 1277-1283, 2013.

[30] F. Ramadhani, Midwives' Competency for Implementation of Active Management of Third Stage of Labor in Dar es Salaam Municipal Hospitals, Muhimbili University of Health and Allied Sciences, Dar es Salaam, Tanzania, 2011.

[31] D. Nigussie, Assessement of Knowledge and Practice of Obstetric Care Providers toward Active Management of Third Stage of Labor at Public Health Centers in the Towns of Finfine Area Special Zone of Oromia Regional State, Addis Ababa University, Addis Ababa, Ethiopia, 2017. 